\title{
Systemic Infection of Maize, Sorghum, Rice, and Beet Seedlings with Fumonisin- Producing and Nonproducing Fusarium verticillioides Strains
}

\author{
Raana Dastjerdi ${ }^{1,2}$ and Petr Karlovsky ${ }^{2 *}$ \\ ${ }^{I}$ Seed and Plant Improvement Research Institute (SPII), Karaj, Iran \\ ${ }^{2}$ Molecular Phytopathology and Mycotoxin Research, Georg-August-University Göttingen, Grisebachstrasse 6, 37077 Göt- \\ tingen, Germany \\ (Received on May 26, 2015; Revised on July 22, 2015; Accepted on July 27, 2015)
}

Two fumonisin-nonproducing strains of Fusarium verticillioides and their fumonisin producing progenitors were tested for aggressiveness toward maize, sorghum, rice, and beetroot seedlings grown under greenhouse conditions. None of the plants showed obvious disease symptoms after root dip inoculation. Fungal biomass was determined by species-specific real-time PCR. No significant $(P=0.05)$ differences in systemic colonization were detected between the wild type strains and mutants not producing fumonisins. $F$. verticillioides was not detected in any of the non-inoculated control plants. The fungus grew from roots to the first two internodes/ leaves of maize, rice and beet regardless of fumonisin production. The systemic growth of $F$. verticillioides in sorghum was limited. The results showed that fumonisin production was not required for the infection of roots of maize, rice and beet by $F$. verticillioides.

Keywords : Fusarium verticillioides, fumonisins, maize

Fumonisins are polyketide mycotoxins that contaminate maize-based foodstuffs and animal feeds worldwide (Anukul et al., 2014; Castellá et al., 1999; da Silva et al., 2000; Munkvold and Desjardins, 1997). Although a number species of Fusarium, including $F$. anthophilum, F. fujikuroi, $F$. nygamai, $F$. oxysporum and $F$. proliferatum produce fumonisins, $F$. verticillioides (Sacc.) Nirenberg is of particular concern (Munkvold and Desjardins, 1997). This fungus is a common ear rot pathogen of maize (Zea mays)

\footnotetext{
*Corresponding author.

Phone) +49-551-3912918, FAX) +49-551-398177

E-mail)pkarlov@gwdg.de

This is an open access article distributed under the terms of the Creative Commons Attribution License (http://creativecommons.org/licenses/by/2.0), which permits unrestricted use, distribution, and reproduction in any medium, provided the original work is properly cited.
}

and can also infect maize stalks and roots without causing visible symptoms of disease (Munkvold and Desjardins, 1997; Nelson et al., 1993). Latent infections of maize stalk for extended periods of time have been demonstrated (Munkvold et al., 1997). Since the discovery of fumonisins (Bezuidenhout et al., 1988), these toxins have been studied extensively due to their effects on the health of humans and animals (Nelson et al., 1993), which were explained by interference with sphingolipid metabolism (Wang et al., 1991). More than 10 fumonisins have been characterized, of which fumonisin B1 (FB1) is the most abundant in naturally contaminated maize. Other B-series fumonisin homologues including FB2, FB3 and FB4 make up 10-20\% of the total fumonisins in infected maize (Nelson et al., 1993). A gene cluster involved in fumonisin synthesis comprises 16 genes (Brown et al., 2007).

FB1 occurs in maize all over the world, including Europe. In southern European countries such as Italy, $F$. verticillioides and another source of FB1, F. proliferatum (Bottalico et al., 1995; Logrieco et al., 1995), are the fungi most frequently isolated from infected maize. Fumonisin levels in maize grain inoculated with $F$. verticillioides can reach several grams per kilogram (Han et al., 2014). High levels of FB1 in maize have been reported in Italy (reviewed in Logrieco et al., 2002). F. verticillioides is also the Fusarium species most frequently isolated from maize grains grown in tropical countries (Adejumo et al., 2007). The level of FB1 in maize grain produced in central and North-Eastern Europe are significantly lower (Usleber et al., 1994). F. verticillioides was also observed to colonize wheat, barley, soybean (Castellá et al., 1999), sorghum (da Silva et al., 2000; dos Reis et al., 2010), rice (Bhargava et al., 1979; Kushiro et al., 2008; Maheshwar et al., 2009; Tansakul et al., 2012) and banana (Glenn et al., 2008). Most recent commodities found to harbor $F$. verticillioides are wine grapes (Mikusova et al., 2013) and blueberries (Munitz et al., 2014). 
The toxicity of fumonisins to plants has been demonstrated (Lamprecht et al., 1994) but the role of fumonisins in pathogenicity remains controversial. Indirect evidence indicates that fumonisins may play a role in maize seedling diseases caused by $F$. verticillioides (Gilchrist, 1998). Desjardins et al. (1995) reported that fumonisin production was important for virulence of $F$. verticillioides on maize seedlings but not in maize blight disease. On the other hand, Jardine and Leslie (1999) showed that a natural fumonisin-nonproducing strain of $F$. verticillioides could infect mature maize plants in the greenhouse with the same aggressiveness as a fumonisin producing strain, causing stalk rot. More recent studies have shown that fumonisins possibly contributed to maize seedling diseases caused by $F$. verticillioides (Glenn et al., 2008; Williams et al., 2007). Regarding maize ear rot, Desjardins and Plattner (2000) compared three natural FB1-nonproducing strains with fumonisin-producing strains under field conditions. Both groups of the strains had the same capability to cause maize ear rot. The studies conducted with natural variants were extended by fumonisin non-producing mutants generated by genetic transformation and compared with isogenic strains producing fumonisins. The results obtained with two independent fumonisin non-producing mutants in field tests indicated that fumonisins are not necessary to cause maize ear infection by $F$. verticillioides (Desjardins et al., 2002). Observation of maize grains colonized with $F$. verticillioides but containing only low amounts of fumonisins (Adejume et al., 2007) supports this view. The biological function of fumonisins in maize ear rot etiology thus remains unclear (Munkvold, 2003). Fumonisins may play a role in other aspects of ecology of $F$. verticillioides.

In this study, we examined the biological function of fumonisins in the growth of $F$. verticillioides in maize and other potential hosts. We assume that maize silks/ cobs is a special environment that only became available for $F$. verticillioides few dozen thousands years ago, which is too short to develop fumonisin biosynthesis, and that fumonisin synthesis originated on hosts other than maize and in tissues other than silks/cobs. Therefore, we employed fumonisin-nonproducing strains and isogenic wild type strains to determine whether fumonisins are virulence factors for $F$. verticillioides on sorghum, rice and beetroot as well as maize. Understanding the role of fumonisin in pathogenicity can help pathologists in finding strategies to control maize diseases and reduce mycotoxin contamination.

\section{Material and Methods}

Fungal strains and inoculum preparation. Two mutants of $F$. verticillioides and their progenitor strains were kindly provided by Dr. Robert Proctor from National Center for Agricultural Utilization Research, United States Department of Agriculture-Agricultural Research Service (USDA-ARS), Peoria, USA. GFA2364 (Proctor et al., 1999 ) is a fumonisin non-producing mutant derived from virulent wild-type strain M-3125 (Proctor et al., 2002), which is representative for FB1, FB2, and FB3 producing strains. Another mutant used in this study was GFA2556, a fumonisin non-producing mutant and its progenitor 109-R7 (Desjardins et al., 2002) as a FB2-producing strain. Both M-3125 and 109-R-7 were designated as wild type FUM 1-1 alleles. This wild type functional allele was replaced with the mutant fum 1-3 allele to generate GFA2364. Mutant GFA2556 with mutant allele fum 1-4 was generated by gene disruption in 109-R-7.

Conidia from all four strains were produced for inoculum by growing the fungus on liquid mung bean media (Bai and Shaner, 1996) at $25^{\circ} \mathrm{C}$ for 5-7 days. The cultures were filtered through sterile cheesecloth and centrifuged at 7,300 $\mathrm{g}$ for $10 \mathrm{~min}$. The spores were re-suspended in $15 \%(\mathrm{v} / \mathrm{v})$ glycerol and their concentration was estimated in a Thoma Chamber $\left(0.0025 \mathrm{~mm}^{2}\right)$. The spore suspensions were stored at $-70^{\circ} \mathrm{C}$. Prior to inoculation, spores were checked for viability on potato dextrose agar (PDA) (Roth, Karlsruhe, Germany) plates and conidial suspensions were diluted to 1 $\times 10^{6}$ spore $\mathrm{ml}^{-1}$ with sterile tap water.

Greenhouse tests. Mini maize cultivar 'Gaspe Flint landrace' (originally collected in Quebec, Canada, provided by Prof. Dr. J. Schirawski, Albrecht-von-Haller Institute for Plant Sciences, University of Göttingen, Germany), Rice genotype 'Taichung Sen 10 (TCS 10)' (obtained from Africa Rice Center, Cotonou, Benin), Sorghum bicolor 'Tall Polish' cultivar (originating from Leibniz Institute of Plant Genetics and Crop Plant Research in Gatersleben, provided by Prof. Dr. J. Schirawski, Albrecht-von-Haller Institute for Plant Sciences, University of Göttingen, Germany), and Weiße Bete (Beetroot) cultivar 'Weißer Kegel' (BioSaatgut Gaby Krautkrämer, Armsheim) were used in this study. The seeds of beetroot, maize and sorghum were surface disinfected in $1 \%(\mathrm{v} / \mathrm{v})$ sodium hypochlorite $(\mathrm{NaClO})$ solution for $1 \mathrm{~min}$ and the absence of Fusaium 
spp. propagules in or on the seeds was verified by plating a representative sample on PDA prior to the greenhouse experiments. The seeds were then sown in plastic multipots containing sterile fine sand $(<2 \mathrm{~mm}$ granularity). Two to three seeds of each cultivar were planted per cavity and thinned to one plant when seedlings appeared. The multipots were maintained at $22^{\circ} \mathrm{C}$ and a relative humidity of $60 \%$ with alternating 12-h light (mercury vapour lamps, 6600 lux at ear height) and dark periods. The rice seeds were placed on wet paper towel and incubated at $25^{\circ} \mathrm{C}$ at darkness. Germinated rice seeds were transferred to pots containing a mixture of sterile commercial plant substrate (Fruhstorfer Erde, Typ T25, HAWITA Group, Vechta, Germany), sand and compost $(1: 1 / 2: 1)$ and placed at $30^{\circ} \mathrm{C}$ with $70-75 \%$ humidity. Two or three weeks after germination, all seedlings were inoculated with conidial spore suspension.

Root-dip inoculation method was employed by soaking the roots of individual plants in spore suspension for 30 min. After inoculation, the seedlings were transferred to new pots $(9 \times 9 \times 9.5 \mathrm{~cm})$ with sterile mixed soil consisting of commercial plant substrate and sand (1:1). The plants were maintained under the same conditions as described above for each cultivar. Plants were irrigated with tap water as required. After one week of inoculation, the plants were supplemented (twice during the growth) with a 1510-15 (N-P-K) soluble fertilizer. Rice seedlings were irrigated weekly with fertilizer containing N-P-K and Fe. Ten replicate pots were set up for each treatment. For rice, number of replications was ten with two plants per pot and the experiment was conducted two times. Control treatments were inoculated with autoclaved tap water. The plants were inspected at weekly intervals for symptoms. Seven to nine (for sorghum) weeks after inoculation, the plants were harvested and the roots were washed carefully under tap water. The sorghum, maize and rice plants were cut into three parts including roots, the first two or three internodes above the soil line and upper plant part and then placed separately in plastic bags. In the case of beetroot plants, they were divided into two parts: root and shoot. In order to quantify the fungal biomass in artificial inoculated plants and determine the possibly function of fumonisins, the harvested plant materials were freeze dried and prepared for further experiments by real-time PCR (qPCR) assay.

DNA extraction and determination of matrix effects. Total genomic DNA was extracted by using 30-60 mg of fine powder plant material based on the CTAB method according Brandfass and Karlovsky (2008). DNA qual- ity and concentration was estimated by electrophoresis in $0.8 \%(w / v)$ agarose gel (Cambrex, Rockland, ME, USA), prepared in TAE buffer ( $40 \mathrm{mM}$ Tris, $1 \mathrm{mM}$ ethylene diamine tetra acetic acid, $\mathrm{pH}$ set to 8.5) (both substances were obtained from Carl Roth, Karlsruhe, Germany). DNA was stained with ethidium bromide $\left(0.5 \mu \mathrm{g} \mathrm{ml}^{-1}\right)$ (Applichem, Darmstadt, Germany) and visualized using a digital imaging system (VilberLourmat, Marne La Vallee, France).

Quantification of fungal DNA by qPCR. Thermocycler $\left(\mathrm{CFX} 384^{\mathrm{TM}}\right.$ Real-Time System, C1000 ${ }^{\mathrm{TM}}$ Thermal Cycler, BioRad, USA) with 384-well microplates (Kisker Biotech GmbH, Steinfurt, Germany) was used for qPCR analysis in a total volume of $4 \mu \mathrm{l}$. The Primer pairs VER 1 (CTTCCTGCGATGTTTCTCC) and VER 2 (AATTGGCCATTGGTATTATATATCTA) designed by Mulle et al. (2004) were used to amplify a 578 bp fragment, which were confirmed to be specific for $F$. verticillioides (Nutz et al., 2011). The reaction mixture contained $2.5 \mathrm{mM} \mathrm{MgCl}_{2}, 0.3 \mu \mathrm{M}$ of each primer and SYBR Green I (Invitrogen, Karlsruhe, Germany) (Nutz et al., 2011). The cycling conditions were as follows: 1 cycle of $2 \mathrm{~min}$ at $95^{\circ} \mathrm{C}, 34$ cycles of $30 \mathrm{~s}$ at $94^{\circ} \mathrm{C}$ (denaturalization), $30 \mathrm{~s}$ at $62.5^{\circ} \mathrm{C}$ (annealing), $40 \mathrm{~s}$ at $72^{\circ} \mathrm{C}$ (extension) and followed by a final extension cycle at $72^{\circ} \mathrm{C}$ for $5 \mathrm{~min}$. Fluorescent data were obtained during the annealing phase to construct a melting curve at the end of assay. The qPCR was completed by running a melting curve analysis. Quantity of fungal biomass was calculated and employed as a parameter of fungal development.

Data processing and statistical analysis. The software SigmaPlot 12.3 Notebook was used for statistical analysis. Melting curve analysis was used to confirm positive samples. The lowest DNA standard employed in qPCR assays was considered as the limit of quantification (LOQ). DNA quantity for samples containing less $F$. verticillioides DNA than LOQ was substituted by LOQ/2 (Hornunga and Reeda, 1990).

\section{Results}

To determine the effect of plant matrix on qPCR, we mixed DNA from uninfected plants in varying dilutions (1:25, $1: 50,1: 100)$ with defined concentration of $F$. verticillioides DNA. The difference in $\mathrm{Ct}$ values between pure standard DNA and standard DNA mixed with plant DNA was considered as an indicator of matrix effects. All plant extracts exerted detectable effects on the $\mathrm{Ct}$ value. The results are 
Table 1. Effect of plant matrix on qPCR

\begin{tabular}{|c|c|c|c|c|c|}
\hline \multirow[b]{2}{*}{ Template } & \multicolumn{5}{|c|}{ Ct of qPCR for $F$. verticilliuides in plant DNA matrix } \\
\hline & Maize & Sorghum & Beetroot & $\begin{array}{c}\text { Rice } \\
\text { (without BSA) }\end{array}$ & $\begin{array}{c}\text { Rice } \\
\text { (with BSA) }\end{array}$ \\
\hline Root DNA (undiluted) & NA & NA & NA & NA & NA \\
\hline Root DNA 1:25 & NA & NA & NA & NA & NA \\
\hline Root DNA 1:50 & NA & NA & NA & NA & NA \\
\hline Root DNA 1:100 & NA & NA & NA & NA & NA \\
\hline Shoot DNA (undiluted) & NA & NA & NA & NA & NA \\
\hline Shoot DNA 1:25 & NA & NA & NA & NA & NA \\
\hline Shoot DNA 1:50 & NA & NA & NA & NA & NA \\
\hline Shoot DNA 1:100 & NA & NA & NA & NA & NA \\
\hline F.v. & 28.53 & 28.53 & 25.62 & 25.92 & 25.79 \\
\hline F.v. $+\operatorname{root} \mathrm{DNA}$ & NA & NA & NA & NA & 28.33 \\
\hline F.v. + root DNA 1:25 & NA & NA & 27.93 & 28.80 & 26.80 \\
\hline F.v. $+\operatorname{root}$ DNA 1:50 & 30.05 & 29.98 & 25.27 & 28.95 & 26.03 \\
\hline F.v. $+\operatorname{root}$ DNA 1: 100 & 28.84 & 28.07 & 25.41 & 28.78 & 26.09 \\
\hline F.v. + shoot DNA & NA & 29.63 & 28.08 & 30.11 & 27.79 \\
\hline F.v. + shoot DNA $1: 25$ & 29.06 & 28.63 & 25.98 & 28.18 & 26.06 \\
\hline F.v. + shoot DNA 1:50 & 28.30 & 27.91 & 25.44 & 28.38 & 25.90 \\
\hline F.v. + shoot DNA 1:100 & 28.19 & 27.99 & - & 28.12 & 26.08 \\
\hline
\end{tabular}

Bold letters are the $\mathrm{Ct}$ values achieved at the dilution that was selected for the work.

F.v. DNA was used at a concentration of $4.5 \mathrm{pg}^{-1} \mathrm{l}^{-1}$ for maize and sorghum and $16.6 \mathrm{pg} \mu \mathrm{l}^{-1}$ for beetroot and rice.

BSA: bovine serum albumin; NA: no amplification.

presented in Table 1. High qPCR inhibition was seen in the root extracts, therefore 100-times dilution for maize and sorghum DNA and 50-times dilution of beetroot DNA were necessary. Dilution 1:25 was used for aboveground tissues of sorghum and beetroot and 1:50 for aboveground maize parts; at these dilutions, $\mathrm{Ct}$ values were not affected by plant matrix. In the case of rice plant material, DNA dilution, even 100-fold, was insufficient to eliminate the effect of plant inhibitors. Adding $1 \mathrm{mg} \mathrm{ml}^{-1}$ bovine serum albumin (BSA) to the reaction mixture together with 1:50 dilution eliminated the matrix effect. These conditions were used for qPCR analysis.

We compared the ability of two FUM 1-1 strains and the mutants derived from them (fum 1-3 and fum 1-4) to cause disease in maize, grain sorghum, beetroot and rice seedlings. None of the studied plants show any visible disease
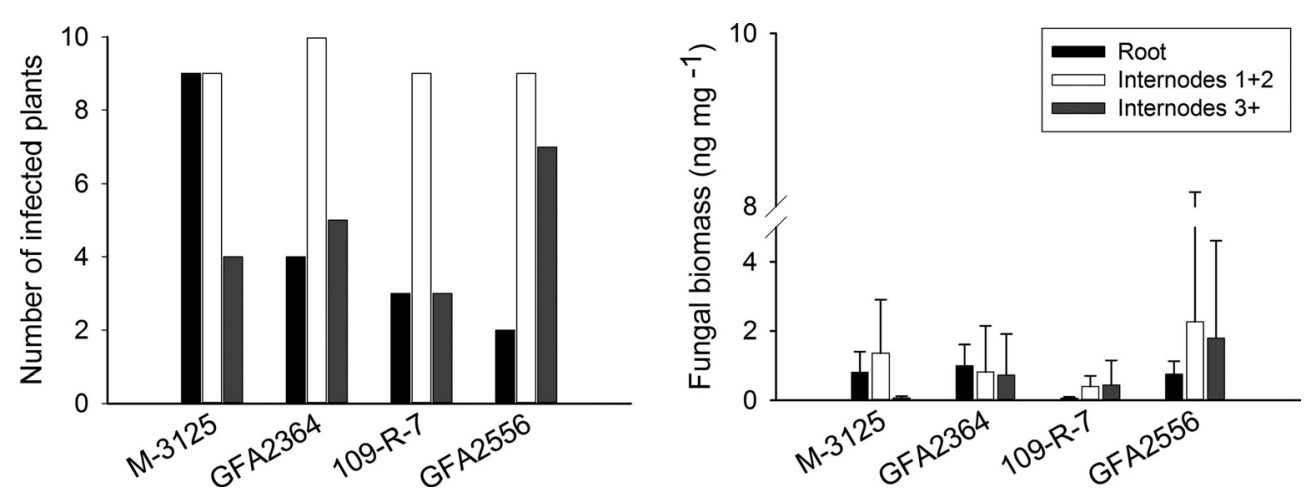

Fig. 1. Infection of maize seedlings with fumonisin producers and nonproducers of $F$. verticillioides. Ten plants were inoculated by dipping the roots in spore suspension. Disease incidence (left) and fungal DNA in infected plants (right) are shown. Limit of quantification (LOQ) was $85 \mathrm{pg} \mathrm{mg}^{-1}$ for root samples and $51 \mathrm{pg} \mathrm{mg}^{-1}$ for internodes. M-3125: a strain producing FB1, FB2 and FB3; GFA2364: fumonisin non-producing mutant of M-3125; 109-R-7: a strain producing FB2; GFA2556: fumonisin non-producing mutant of $109-\mathrm{R}-7$. 

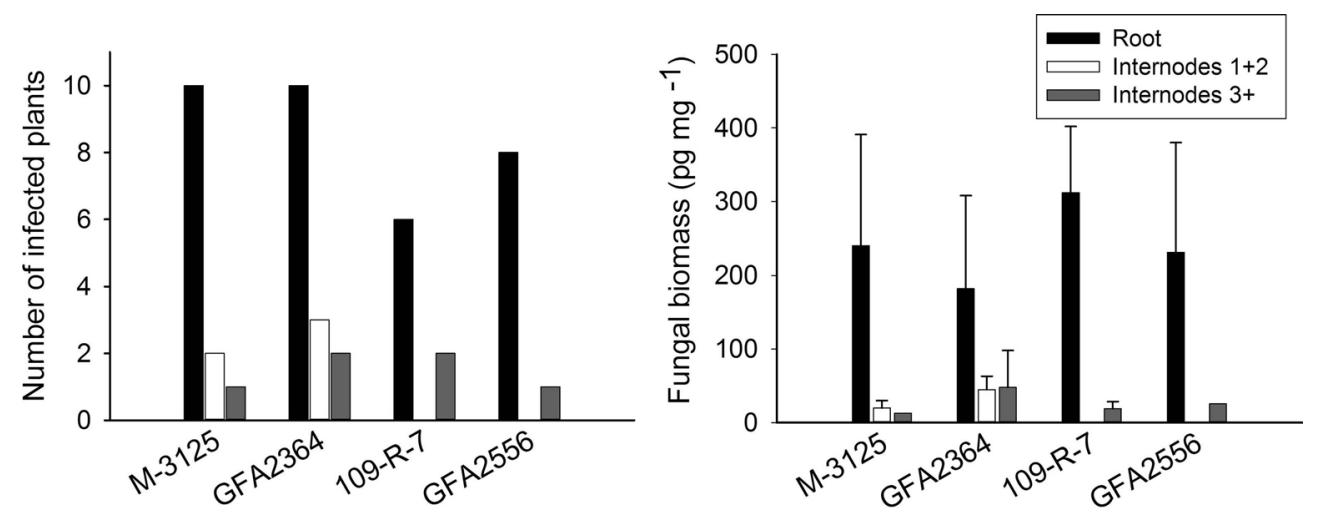

Fig. 2. Infection of sorghum seedlings with fumonisin producers and nonproducers of $F$. verticillioides. Ten plants were inoculated by dipping the roots in spore suspension. Disease incidence (left) and fungal DNA in infected plants (right) are shown. Limit of quantification (LOQ) was $85 \mathrm{pg} \mathrm{mg}^{-1}$ for root samples and $25 \mathrm{pg} \mathrm{mg}^{-1}$ for internodes. M-3125: a strain producing FB1, FB2 and FB3; GFA2364: fumonisin non-producing mutant of M-3125; 109-R-7: a strain producing FB2; GFA2556: fumonisin non-producing mutant of $109-\mathrm{R}-7$.
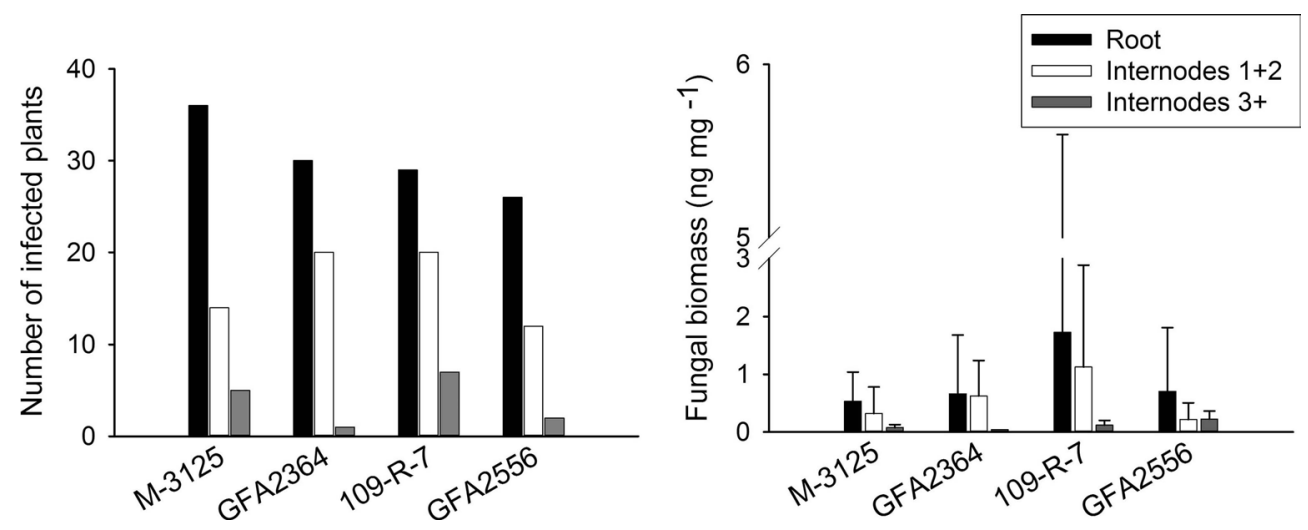

Fig. 3. Infection of rice seedlings with fumonisin producers and nonproducers of $F$. verticillioides. 40 plants were inoculated by dipping the roots in spore suspension. Disease incidence (left) and fungal DNA in infected plants (right) are shown. Limit of quantification (LOQ) was $85 \mathrm{pg} \mathrm{mg}^{-1}$ for root samples and $42 \mathrm{pg} \mathrm{mg}^{-1}$ for internodes. M-3125: a strain producing FB1, FB2 and FB3; GFA2364: fumonisin non-producing mutant of M-3125; 109-R-7: a strain producing FB2; GFA2556: fumonisin non-producing mutant of 109-R-7.
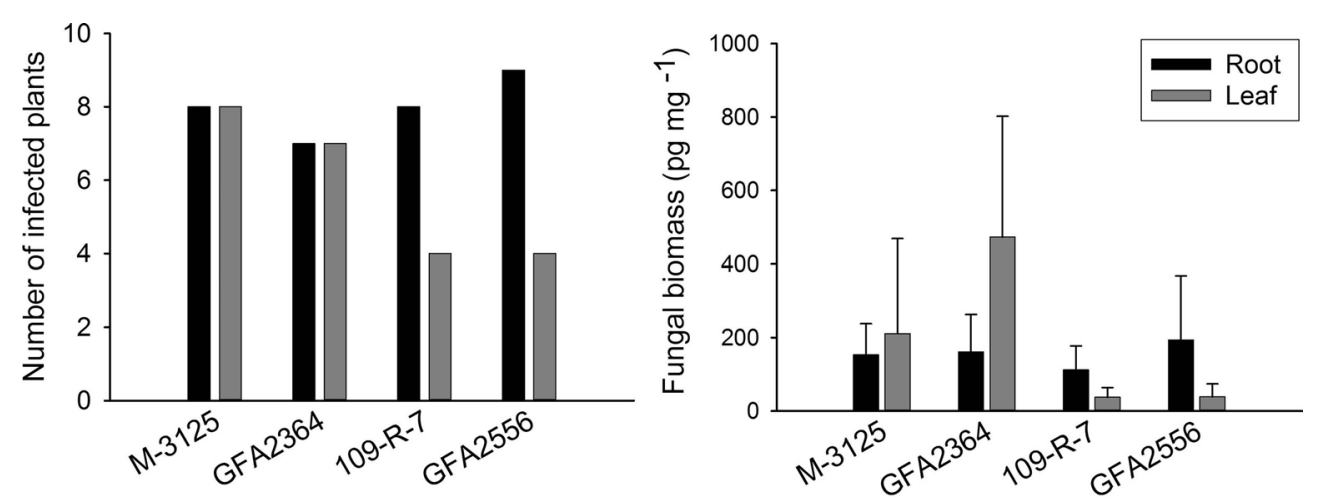

Fig. 4. Infection of beet seedlings with fumonisin producers and nonproducers of $F$. verticillioides. Ten plants were inoducated by dipping the roots in spore supsnesion. Disease incidence (left) and fungal DNA in infected plants (right) are shown. Limit of quantification (LOQ) was $63 \mathrm{pg} \mathrm{mg}^{-1}$ for root samples and $31 \mathrm{pg} \mathrm{mg}^{-1}$ for leaves. M-3125: a strain producing FB1, FB2 and FB3; GFA2364: fumonisin non-producing mutant of M-3125; 109-R-7: a strain producing FB2; GFA2556: fumonisin non-producing mutant of 109-R-7. 
symptoms after root infection. Some necrosis spots were observed on rice leaves in plants infected with fumonisin producing and non-producing strains but $F$. verticillioides was not detected in any of these leaf samples. At the lack of disease symptoms, plants might not be affected by the fungus growing endophytically. Therefore, fungal biomass in plant tissue quantified by real-time PCR was used as an indicator of fungal aggressiveness. In all plants tested, no significant difference $(P=0.05)$ in aggressiveness was detected between wild type strains and corresponding fumonisin-nonproducing mutants. $F$. verticillioides was not detected in any of control plants. Disease incidence in infection caused by $F$. verticillioides in maize, sorghum, rice, and beetroot is presented in left parts of Figs. 1, 2, 3 and 4, respectively. Fungal transmission from roots to the first two internodes/leaves in maize and beetroot occurred but a low systemic infection rate was observed for rice and sorghum. The lack of significant difference between fumonisinproducing and non-producing strains in tissue colonization supported the view that fumonisin was not a virulent factor in our system.

\section{Discussion}

F. verticillioides is the most prevalent fungus associated with maize seedling diseases, ear rot and stalk rot (Logrieco et al., 2002; Srobarova et al., 2002). Fungus can colonize stalks without any visible disease symptoms (Kedera et al., 1992; Munkvold and Carlton, 1997; Munkvold et al., 1997). The role of fumonisins in virulence is still not certain. In this study, two fumonisin non-producing strains and their progenitors were employed to examine the possible role of these toxin in the infection of maize, grain sorghum, rice and beetroot seedlings. There was no relationship between fungal aggressiveness and fumonisin production in the plants studied.

Regarding the maize plants, movement of the fungus from inoculated roots to the remainder of plant occurred regardless of whether the strain produced fumonisin or not. The rate of symptomless systemic colonization was lower above the second internodes in stalks. Munkvold et al. (1997) showed that restricted movement of fungus from maize seed or crown to higher internodes in stalk limits systemic colonization of kernels. However, other studies provide evidence that systemic infection may contribute to contamination of kernels by mycotoxins (Desjardins et al., 2002; Desjardins and Plattner, 2000). Systemic infection by $F$. verticillioides is supported by higher temperatures (Williams and Munkvold, 2008). There was no significant difference between fungal biomass of each wild type strain and their mutants. Although high level of fungal biomass was observed in the first two stalk internodes, it was independent of fumonisin production. The GFA2364 and GFA2556 strains make no fumonisins in vitro (Desjardins et al., 2002), but in our experiments these two strains caused significant colonization of tissues at the same level of fumonisin-producing strains. The results indicated that fumonisin production was not required for $F$. verticillioides to colonize the maize tissues following root inoculation.

In the case of sorghum, after root inoculation the fungus remained in the below ground tissues; its spread to the shoot was limited. Only $20-30 \%$ of the plants inoculated with M-3125 strain and its mutant were colonized with the fungus in the first two internodes. This can be explained by host preference of the mating population A (MPA) of Gibbrella fujikuroi for maize, while mating population $\mathrm{F}$ (MPF) of G. fujikuroi can infect sorghum plants, too (Leslie et al., 1992). The selection of adequate Fusarium species is therefore important in breeding programs (Jardine and Leslie, 1999). It is also possible that the sorghum variety used in this study was partially resistant, limiting the spread of the pathogen.

Maize silks and cobs only became available for infection a few thousands years ago. For millions of years, the fungus might have infected plant roots or stems, living as an endophyte. Fumonisin synthesis might have been maintained by selection pressure exerted by hosts other than maize and in tissues other than silks or cobs. The presence of fungus in upper internodes, while it is absent in lower nodes (as was the case for two plants inoculated with 109R-7 strain and one plant inoculated with GFA2556 strain), can be explained by spore splashing during the inoculation or by microconidia carried by the transpiration stream from roots to upper stem. Based on our data we cannot conclusively estimate the role of fumonisin in the infection of on sorghum seedlings.

The fungus developed inside young plants of rice and beetroot but the aggressiveness of wild type strains and their mutants was not statistically different. Fumonisins have been reported in rice, though not as frequently as in maize (Kushiro et al., 2008; Maheshwar et al., 2009; Tansakul et al., 2012). F. verticillioides was shown to causes panicle rot of rice (Bhargava et al., 1979). Fungi belonging to $G$. fujikuroi complex including MPA ( $F$. verticillioides), MPC (F. fujikuroi) and MPD (F. proliferatum) have been found in naturally infected rice seeds (Desjardins et al., 2000). The authors showed that some strains of $G$. fujikuroi MPD were capable of producing fumonisins as well as beauvericin and moniliformin but not gibberellic acid, which play a key role in bakanae disease of rice. In 
the present study, 15-20 days after inoculation some necrosis spots were observed on rice leaves. The spots were irregular, small, light brown in the center and dark brown at the margins in the initial stage. The necrotic lesions usually developed, joined together, made larger spots and extended along the length of the leaf. The spots were seen regardless of fumonisin or non-fumonisin producing strain tested. However, qPCR has not detected the fungus in the leaves. Control plants did not show any necrotic spots. Rice experiments were conducted twice (in summer 2012 and winter 2013) and the results were identical. Further assessments are, therefore, necessary to understand the etiology of these necrotic spots.

$F$. verticillioides causes seedling damping-off in sugar beet and has been reported as a pathogen which can produce symptoms similar to fusarium yellows (Hanson and Hill, 2004).

Potential inhibitors of PCR such as proteins, polyphenols, polysaccharides, and secondary metabolites (Horne et al., 2004) are released during DNA extraction from plants. These compounds can prevent amplification, increase $\mathrm{Ct}$ values or reduce efficiency and reproducibility of PCR (Cankar et al., 2006; Demeke and Jenkins, 2010). In this study, the effect of plant matrix on qPCR reactions was assessed by adding pure F.v. DNA to the DNA of uninfected plants. Undiluted plant extracts completely inhibited qPCR (Table 1). Dilution of DNA samples is a simple method to reduce inhibitor concentration but it decreases PCR sensitivity (Demeke and Jenkins, 2010). In this study, dilutions 1:25 or 1:50 for the aboveground plant tissues and 1:100 for the root samples were necessary. Amplification of DNA extracted from rice plants was further improved by adding bovine serum albumin, which has been shown to deactivate PCR inhibitors in various kinds of samples including plant materials (Plante et al., 2010; Wei et al., 2008).

Maize seedlings colonization with fumonisin non-producing strains and fumonisin-producing strains was similar; it is therefore possible that nonproducing strains can be used as biocontrol control agents reducing fumonisin content in maize (Desjardins and Plattner, 2000), particularly under conditions leading to symptomless infection (Kedera et al., 1999; Munkvold et al., 1997).

\section{Acknowledgments}

We thank Prof. Dr. J. Schirawski (Albrecht-von-Haller Institute for Plant Sciences, University of Göttingen, Germany) for kindly providing the dwarf maize seeds and sorghum cultivar. We further thank Prof. Dr. R. H. Proctor (Mycotoxin Research, National Center for Agricultural
Utilization Research, United States Department of Agriculture-Agricultural Research Service (USDA-ARS), Peoria, USA.) who kindly supplied the $F$. verticillioides strains.

\section{References}

Adejumo, T. O., Hettwer, U. and Karlovsky, P. 2007. Survey of maize from south-western Nigeria for zearalenone, alphaand beta-zearalenols, fumonisin B1 and enniatins produced by Fusarium species. Food Add. Contam. 24:993-1000.

Anukul, N., Maneeboon, T., Roopkham, C., Chuaysrinule, C. and Mahakarnchanakul, W. 2014. Fumonisin and T-2 toxin production of Fusarium spp. isolated from complete feed and individual agricultural commodities used in shrimp farming. Mycotoxin Res. 30:9-16.

Bai, G. H. and Shaner, G. 1996. Variation in Fusarium graminearum and cultivar resistance to wheat scab. Plant Dis. 80:975-979.

Bezuidenhout, S. C., Gelderblom, W. C. A., Gorst-Allman, C. P., Horak, R. M., Marasas, W. F. O., Spiteller, G. and Vleggaar, R. 1988. Structure elucidation of the fumonisins, mycotoxins from Fusarium moniliforme. J. Chem. Soc. Chem. Commun. 11:743-745.

Bhargava, S. N., Shukla, D. N., Singh, N. K. and Singh, N. 1979. Fusarium moniliforme causing panicle rot of rice. Indian Phytopathol. 31:367-369.

Bottalico, A., Logrieco, A., Ritieni, A., Moretti, A., Randazzo, G. and Corda, P. 1995. Beauvericin and fumonisin B1 in preharvest Fusarium moniliforme maize ear rot in Sardinia. Food Addit. Contam. 12:599-607.

Brown, D. W., Butchko, R. A. E., Busman, M. and Proctor, R. H. 2007. The Fusarium verticillioides FUM gene cluster encodes a Zn(II)2Cys6 protein that affect FUM gene expression and fumonisin production. Eukaryot. Cell 6:1210-1218.

Cankar, K., Stebih, D., Dreo, T., Zel, J. and Gruden, K. 2006. Critical points of DNA quantification by real-time PCR effects of DNA extraction method and sample matrix on quantification of genetically modified organisms. BMC. Biotech. 6:37-51.

Castellá, G., Bragulat, M. R. and Cabañes, F. J. 1999. Surveillance of fumonisins in maize-based feeds and cereals from Spain. J. Agric. Food Chem. 47:4707-4710.

da Silva, J. B., Pozzi, C. R., Mallozzi, M. A., Ortega, E. M. and Corrêa, B. 2000. Mycoflora and occurrence of aflatoxin B1 and fumonisin B1 during storage of Brazilian sorghum. $J$. Agric. Food Chem. 48:4352-4356.

Demeke, T. and Jenkins, G. R. 2010. Influence of DNA extraction methods, PCR inhibitors and quantification methods on real-time PCR assay of biotechnology-derived traits. Anal. Bioanal. Chem. 396:1977-1990.

Desjardins, A. E., Munkvold, G. P., Plattner, R. D. and Proctor, R. H. 2002. FUM1-A gene required for fumonisin biosynthesis but not for maize ear rot and ear infection by Gibberella 
moniliformis in field tests. Mol. Plant-Microbe Interact. 15:1157-1164.

Desjardins, A. E., Manandhar, H. K., Plattner, R. D., Manandhar, G. G., Poling, S. M. and Maragos, C. M. 2000. Fusarium species from Nepalese rice and production of mycotoxins and gibberellic acid by selected species. Appl. Environ. Microbiol. 66:1020-1025.

Desjardins, A. E. and Plattner, R. D. 2000. Fumonisin B1nonproducing strains of Fusarium verticillioides cause maize (Zea mays) ear infection and ear rot. J. Agric. Food Chem. 48:5773-5780.

Desjardins, A. N., Plattner, R. D., Nelsen, T. C. and Leslie, J. F. 1995. Genetic analysis of fumonisin production and virulence of Gibberella fujikuroi mating population A (Fusarium moniliforme) on maize (Zea mays) seedlings. Appl. Environ. Microbiol. 61:79-86.

dos Reis, T. A., Zorzete, P., Pozzi, C. R., da Silva, V. N., Ortega, E. and Correa, B. 2010. Mycoflora and fumonisin contamination in Brazilian sorghum from sowing to harvest. J. Sci. Food Agric. 90:1445-1451.

Gilchrist, D. G. 1998. Programmed cell death in plant disease: the purpose and promise of cellular suicide. Annu. Rev. Phytopathol. 36:393-414.

Glenn, A. E., Zitomer, N. C., Zimeri, A. M., Williams, L. D., Riley, R. T. and Proctor, R. H. 2008. Transformation-mediated complementation of a FUM gene cluster deletion in $\mathrm{Fu}$ sarium verticillioides restores both fumonisin production and pathogenicity. Mol. Plant-Microbe Interact. 21:87-97.

Han, Z., Tangni, E. K., Huybrechts, B., Munaut, F., Scauflaire, J., Wu, A. and Callebaut, A. 2014. Screening survey of co-production of fusaric acid, fusarin C, and fumonisins B1, B2 and B3 by Fusarium strains grown in maize grains. Mycotoxin Res. 30:231-240.

Hanson, L. E. and Hill, A. L. 2004. Fusarium species causing fusarium yellows of sugarbeet. J. Sugar Beet Res. 41:163-178.

Horne, E. C., Kumpatla, S. P., Patterson, K. A., Gupta, M. and Thompson, S. A. 2004. Improved high-throughput sunflower and cotton genomic DNA extraction and PCR fidelity. Plant Mol. Biol. Rep. 22:83a-83i.

Hornunga, R. W. and Reeda, L. D. 1990. Estimation of average concentration in presence of nondetectable values. Appl. Occup. Environ. Hyg. 5:46-51.

Jardine, D. J. and Leslie, J. F. 1999. Aggressiveness to mature maize plants of Fusarium strains differing in ability to produce fumonisin. Plant Dis. 83:690-693.

Kedera, C. J., Leslie, J. F. and Claflin, L. E. 1992. Systemic infection of corn by Fusarium moniliforme. (Abstr.) Phytopathology 82:1138.

Kushiro, M., Nagata, R., Nakagawa, H. and Nagashima, H. 2008. Liquid chromatographic deletion of fumonisins in rice seeds. Rep. Nat'l. Food Res. Inst. 72:37-44.

Lamprecht, S. C., Marasas, W. F. O., Alberts, J. F., Cawood, M. E., Gelderblom, W. C. A., Shephard, G. S., Thiel, P. G. and Calitz, F. J. 1994. Phytotoxicity of fumonisins and TA-toxin to corn and tomato. Phytopathology 84:383-391.

Leslie, J. F., Plattner, R. D., Desjardins, A. E. and Klittich, C. J. R. 1992. Fumonisin B1 production by strains from different mating populations of Gibberella fujikuroi (Fusarium section Liseola). Phytopathology 82:341-345.

Logrieco, A., Mulè, G., Moretti, A. and Bottalico, A. 2002. Toxigenic Fusarium species and mycotoxins associated with maize ear rot in Europe. Eur. J. Plant Pathol. 108:597-609.

Logrieco, A., Moretti, A., Ritieni, A., Bottalico, A. and Corda, P. 1995. Occurrence and toxigenicity of Fusarium proliferatum from preharvest maize ear rot, and associated mycotoxins in Italy. Plant Dis. 79:727-731.

Maheshwar, P. K., Moharram, S. A. and Janardhana, G. R. 2009. Detection of fumonisin producing Fusarium verticillioides in paddy (Oryza sativa L.) using polymerase chain reaction (PCR). Braz. J. Microbiol. 40:134-138.

Mikusova, P., Srobarova, A., Sulyok, M. and Santini, A. 2013. Fusarium fungi and associated metabolites presence on grapes from Slovakia. Mycotoxin Res. 29:97-102.

Mule, G., Susca, G. S. and Moretti, A. 2004. A species-specific PCR assay based on the calmodulin partial gene for identification of Fusarium verticillioides, $F$. proliferatum and $F$. subglutinans. Eur. J. Plant Pathol. 110:495-502.

Munitz, M. S., Resnik, S. L., Pacin, A., Salas, P. M., Gonzalez, H. H. L., Montti, M. I. T., Drunday, V. and Guillin, E. A. 2014. Mycotoxigenic potential of fungi isolated from freshly harvested Argentinean blueberries. Mycotoxin Res. 30:221-229.

Munkvold, G. P. 2003. Epidemiology of Fusarium diseases and their mycotoxins in maize ears. Eur. J. Plant Pathol. 109:705-713.

Munkvold, G. P. and Carlton, W. M. 1997. Influence of inoculation method on systemic Fusarium moniliforme infection of maize plants grown from infected seeds. Plant Dis. 81:211216.

Munkvold, G. P. and Desjardins, A. E. 1997. Fumonisins in maize: can we reduce their occurrence. Plant Dis. 81:556565.

Munkvold, G. P., McGee, D. C. and Carlton, W. M. 1997. Importance of different pathways for maize kernel infection by Fusarium moniliforme. Phytopathology 87:209-217.

Nelson, P. E., Desjardins, A. E. and Plattner, R. D. 1993. Fumonisins, mycotoxins produced by Fusarium species: biology, chemistry, and significance. Annu. Rev. Phytopathol. 31:233252.

Nutz, S., Doell, K. and Karlovsky, P. 2011. Determination of the LOQ in real-time PCR by receiver operating characteristic curve analysis: application to qPCR assays for Fusarium verticillioides and F. proliferatum. Anal. Bioanal. Chem. 401:717-726.

Plante, D., Bélanger, G., Leblanc, D., Ward, P., Houde, A. and Trottier, Y. L. 2010. The use of bovine serum albumin to improve the RT-qPCR detection of foodborne viruses rinsed from vegetable surfaces. Lett. Appl. Microbiol. 52:239-244.

Proctor, R. H., Desjardins, A. E., McCormick, S. P., Plattner, R. 
D., Alexander, N. J. and Brown, D. W. 2002. Genetic analysis of the role of trichothecene and fumonisin mycotoxins in the virulence of Fusarium. Eur. J. Plant Pathol. 108:691-698.

Proctor, R. H., Desjardins, A. E., Plattner, R. D. and Hohn, T. 1999. A polyketide synthase gene required for biosynthesis of fumonisin mycotoxins in Gibberella fujikuroi mating population A. Fungal. Genet. Biol. 27:100-112.

Srobarova, A., Moretti, A., Ferracane, R., Ritieni, A. and Logrieco, A. 2002. Toxigenic Fusarium species of Liseola section in pre-harvest maize ear rot, and associated mycotoxins in Slovakia. Eur. J. Plant Pathol. 108:299-306.

Tansakul, N., Limsuwan, S. and Trongvanichnam, K. 2012. Fumonisin monitoring in Thai red cargo rice by reversed-phase high-performance liquid chromatography with electrospray ionization ion trap mass spectrometry. Int. Food Res. J. 19:1561-1566.

Usleber, E., Straka, M. and Terplan, G. 1994. Enzyme immunoassay for fumonisin B1 applied to corn-based food. J. Agric.
Food Chem. 42:1392-1396.

Wang, E., Norred, W. P., Bacon, C. W., Riley, R. T. and Merrill, A. H. 1991. Inhibition of sphingolipid biosynthesis by fumonisins. Implications for diseases associated with Fusarium moniliforme. J. Biol. Chem. 266:14486-14490.

Williams, L. D. and Munkvold, G. P. 2008. Systemic infection by Fusarium verticillioides in maize plants grown under three temperature regimes. Plant Dis. 92:1695-1700.

Williams, L. D., Glenn, A. E., Zimeri, A. M., Bacon, C. W., Smith, M. A. and Riley, R. T. 2007. Fumonisin disruption of ceramide biosynthesis in maize roots and the effects on plant development and Fusarium verticillioides-induced seedling disease. J. Agric. Food Chem. 55:2937-2946.

Wei, T., Lu, G. and Clover, G. 2008. Novel approaches to mitigate primer interaction and eliminate inhibitors in multiplex PCR, demonstrated using an assay for detection of three strawberry viruses. J. Virol. Methods 151:132-139. 